\title{
Abstract
}

\section{Knowledge and practises on school disaster preparedness for chemical hazard and associated factors among school teachers in biyagama medical officer of health area}

\author{
Bandaranayake PS ${ }^{1}$, Lokubalasooriya $\mathrm{A}^{2}$, Pathirana $\mathrm{N}^{3}$, Vithanage $\mathrm{V}^{4}$ \\ ${ }^{1}$ Ministry of health, Sri Lanka, ${ }^{2}$ Family Health Bureau, ${ }^{3}$ District general hospital, Negombo, ${ }^{4}$ Medical officer of health \\ office, Kelaniya
}

\section{Key words: Disaster management, knowledge, practices, associated factors, teachers}

\section{Introduction}

Sri Lankan government has taken steps to introduce some legislative and policy efforts on disaster management and promote disaster education in schools. Towards this end, disaster related topics have been incorporated in to the school curricular since students and teachers are the best messengers to the public.

Objective

Objective was to assess the knowledge and practices on school disaster preparedness and describe associated factors among school teachers in Biyagama Medical Officer of Health area.

\section{Methods}

Study was a descriptive cross sectional study by using a sample of 380 teachers who were selected by a proportionate sampling technique. Data was collected by a self administered questionnaire which was made based on 'National Guideline on School Disaster Safety'.

\section{Results}

Majority $(>60 \%)$ of teachers were unaware of the consequence of a disaster, availability of chemical handling factories in the area, and the availability of a disaster preparedness plan in their school. However, $75 \%$ of study subjects knew the practices done in a chemical emergency in a nearby school and $86 \%$ teachers knew what to do in a chemical spill in school laboratory. Majority $(87 \%)$ of study subjects were poor on overall knowledge on disaster preparedness and practices while $95 \%$ of study subjects were unaware of practices in a disaster.

Conclusion

Both Knowledge and Practices in preparedness of a chemical hazard were not adequate. Service duration and teaching subject at school of the study subjects were significant factors associated with knowledge and practices among school teachers. Policy guidelines to assess the disaster drills, training programmes ensuring attendance of all of the schools' population are recommended. Coordinated assistance from Disaster Management Centre and health sector should be arranged. 